\title{
Discussion to paper of Dr Madersbacher
}

\section{Chairman: DR HACHEN}

Chairman. Now the paper by Dr Madersbacher is open for discussion.

DR WENDALle (Belgium). I would like to ask Dr Madersbacher looking at his hydrodynamic studies. Do you think that transurethral sphincterotomy should only be done at a 12 o'clock position?

DR MADERSBACHER. A properly done sphincterotomy in the I2 o'clock position, coming down to the bulbous urethra without hurting it, is in my experience in 90 per cent of the cases an adequate method. You have to go deep down maybe 6-8 millimetres and you may see the fat coming out. If you look at anatomical pictures the striated muscle flattens laterally and there is nearly nothing at the 6 o'clock position. There is not very much in 3 and 9 but the heavy bulk of striated muscle is in the 12 o'clock position. Together with Brantley Scott I described this method which is a simple method. I do not do it now with the loop resection any more. We have designed an electro-knife and it incises precisely. You can see how the ring opens when you cut the striated fibres and you can see where you should end.

DR HARDY (G.B.). We've all heard of the sphincterotomies in a great many positions including the I2 o'clock position. Can I ask for how long do these effects last and how often do you need to do them?

Chairman. Well I may answer partly. As you remember I published a paper in Paraplegia on the 3 and 9 o'clock resections and there we had about I 5 per cent significant re-stenosis after 2 years but I think that Dr Madersbacher's deeper incision at I 2 o'clock is less haemorrhagic and it still needs a follow-up and careful re-evaluation. It doesn't mean that since a patient had sphincterotomy you can lose sight of him but I think that there is functionally a better result than with the 9 o'clock results we had.

DR MADERSBACHER. I fully agree with Dr Hachen, but coming back to your question I feel that we shouldn't do too much in the first sphincterotomy and therefore also we have a rate of 15 per cent maybe going in the long run up to 20 per cent. We are doing this procedure together with Brantley Scott's since ' 73 but we have, you can call it, recurrences in 15 to 20 per cent, but nevertheless I think that is not a big procedure, and if you repeat it one year afterwards why shouldn't you do it. I think that one major advantage which was already mentioned by Dr Hachen in one of his papers is that you really get no change in the erectile function after a 12 o'clock position, which is quite high in patients where you do a sphincterotomy at 12,3 and 9 , probably due to lesions in the nervous and vascular bundle which are in the neighbourhood of the 3 and 9 positions.

SIR Ludwig GuttmanN (G.B.). In addition to Hardy's question, I would like to ask if your approach with excision at $\mathrm{I} 2$ has in your experience proved very successful. How often have you had unsuccessful cases where you had to repeat this operation not at 12 but at 3 or 9 ?

DR MADERSBACHER. If I repeated the operation I did it again at the I2 o'clock position but in addition in some cases I did a transurethral incision of the bladder neck but I never did additional cuts at 3 and 9. On the other hand, if there is a combination with the prostatitis with stones in a rigid urethra, there is no point just to cut at 9,3 and I 2 or wherever you would like. There you have to do a proper transurethral resection which is not an easy operation in these patients. 